\title{
Max: functional domains and interaction with c-Myc
}

\author{
Gregory J. Kato, ${ }^{1,2}$ William M.F. Lee, ${ }^{3}$ Lili Chen, ${ }^{3}$ and Chi V. Dang ${ }^{2,4-6}$ \\ Division of Hematology, Departments of ${ }^{1}$ Pediatrics and ${ }^{4}$ Medicine, ${ }^{5}$ Cell Biology and Anatomy, and ${ }^{6}$ The Johns Hopkins \\ Oncology Center, The Johns Hopkins University School of Medicine, Baltimore, Maryland 21205 USA; $^{3}$ Department \\ of Medicine, University of Pennsylvania School of Medicine, Philadelphia, Pennsylvania 19104-6148 USA
}

The product of the c-myc proto-oncogene is a DNA-binding protein, the deregulated expression of which is associated with a variety of malignant neoplasms. The cDNA for the max gene was recently cloned as a result of the ability of its protein product to interact with the c-Myc protein. We studied bacterially produced Max, c-Myc, and a series of truncated c-Myc proteins. Full-length c-Myc alone cannot bind DNA. However, a truncated c-Myc protein comprising the basic, helix-loop-helix, and leucine zipper regions can bind specifically to DNA bearing the sequence GGGCAC(G/A)TGCCC. Max protein, either alone or in a heteromeric complex with full-length c-Myc, binds to the same core sequence. Using a novel combination of chemical and photo-cross-linking analysis, we demonstrate that either Max or a c-Myc/Max heteromeric complex binds to DNA virtually exclusively in a dimeric structure. Using fusion proteins in cultured cells, we establish a number of functional characteristics of Max. First, we show that Max can interact with c-Myc intracellularly in a manner dependent on the integrity of the helix-loop-helix and leucine zipper motifs. Second, a nuclear localization domain that contains the sequence PQSRKKLR is mapped to the carboxy-terminal region of Max. Third, Max lacks a transcriptional activation domain that is functional in Chinese hamster ovary cells when fused to a heterologous DNA-binding domain. These data suggest that Max may serve as a cofactor for $\mathrm{c}-\mathrm{Myc}$ in transcriptional activation or, by itself, as a transcriptional repressor.

[Key Words: Max; c-Myc; DNA binding; nuclear localization; helix-loop-helix; leucine zipper]

Received September 13, 1991; revised version accepted December 2, 1991.

The product of the c-myc proto-oncogene is a short-lived nuclear phosphoprotein that participates in oncogenesis in a wide variety of experimentally induced and naturally occurring tumors. By homology to a growing family of proteins bearing the helix-loop-helix (HLH) motif, it has been speculated that the c-Myc protein participates in the transcriptional regulation of specific genes (Lüscher and Eisenman 1990). A number of activities have been identified and functionally mapped to various regions of the c-Myc protein, including domains capable of transcriptional activation (Kato et al. 1990), nonspecific DNA binding (Dang et al. 1989a), nuclear localization (Dang and Lee 1988), specific DNA binding (Blackwell et al. 1990; Prendergast and Ziff 1991), and oligomerization (Dang et al. 1989b).

The existence of oligomerization motifs in the c-Myc protein, the HLH and the leucine zipper (ZIP), suggests that c-Myc functions either as a homo-oligomer or a hetero-oligomer. Oligomerization of c-Myc appears to be necessary for its function because inactive mutants of c-Myc with intact oligomerization domains behave as dominant-negative mutants in cell transformation assays, presumably through oligomerization either with

${ }^{2}$ Corresponding authors. wild-type c-Myc or with a c-Myc heteromeric partner protein (Dang et al. 1989b). In contrast, c-Myc mutants with deletions in either the ZIP or HLH domains are recessive-negative mutants. Although purified c-Myc protein produced in bacteria homo-oligomerizes in vitro (Dang et al. 1989b), this homo-oligomerization is likely to be nonphysiological. In additional studies, an assay that can detect protein-protein interactions in cells failed to detect Myc-Myc interaction through its oligomerization domain (Dang et al. 1991). These observations suggest that c-Myc hetero-oligomerization to another protein is required for its function.

By functional cloning, Blackwood and Eisenman (1991) recently identified cDNAs that encode two forms of Max, a protein that binds to c-Myc via the HLH-ZlP domain. The two alternatively spliced max mRNAs encode 151-and 160-amino-acid polypeptides that contain a basic HLH-ZlP (bHLH-ZIP) domain. Either form of Max protein can oligomerize with c-Myc in vitro to bind a specific DNA sequence bearing the core CACGTG. In contrast to the in vitro-translated human Max, which alone cannot bind DNA (Blackwood and Eisenman 1991), the murine Max homolog appears to homo-oligomerize in vitro and bind to the same DNA sequence bound by c-Myc fusion proteins (Prendergast et a. 1991). 
It was reported in these studies that full-length c-Myc alone, which was prepared by in vitro translation in rabbit reticulocyte lysates, also binds DNA specifically. These reports share the unexpected finding that the electrophoretic mobilities of DNA-protein complexes in native gels are identical for Myc alone and Myc/Max hetero-oligomers. It is not known, however, whether the reticulocyte lysates used in these experiments contained Max-like proteins that may have contributed to the c-Myc DNA-binding activity in the electrophoretic mobility gel-shift assays. To avoid contamination from mammalian Max-like activity, we have purified bacterially produced Myc and Max proteins to study their DNA-binding properties.

A model has been proposed in which the activity of c-Myc/Max hetero-oligomers is opposed by Max homooligomers (Cole 1991). According to this model, expression of Max is constitutive, whereas c-Myc expression is induced transiently by growth stimulus. The coexpression of c-Myc and Max allows formation of a c-Myc/Max hetero-oligomer that binds to specific DNA elements and activates transcription through the transcriptional activation domain contributed by c-Myc. Because Max remains present in quiescient cells with low-level expression of c-Myc, Max may function, as a homo-oligomer or with another unknown partner, to repress the same genes that are activated by c-Myc/Max heteromers. This model involves several premises that have not been established clearly in the literature. Specifically, the model supposes that c-Myc protein alone does not bind specifically to DNA; that Max does not alter the DNAbinding specificity of $\mathrm{c}-\mathrm{Myc}$; that Max is able to localize to the nucleus in the absence of c-Myc; that Max lacks its own transcriptional activation domain; and, finally, that c-Myc and Max interact intracellularly. Through an approach utilizing Max fusion proteins expressed in bacterial and mammalian cells, we have sought to explore these molecular characteristics of the Max protein to evaluate this model.

In this report we present in vitro and intracellular analyses of Myc-Max interaction, as well as mapping of functional domains of the Max protein. We identify a region of c-Myc that prevents specific DNA binding by bacterially produced $\mathrm{c}-\mathrm{Myc}$ alone. We demonstrate the DNA-binding specificity of recombinant truncated c-Myc, as well as Max, and the heteromeric complex of c-Myc and Max. We show that DNA binding by these proteins occurs virtually exclusively in dimeric complexes. We show that Max lacks a transcriptional activation domain, possesses a nuclear localization signal, and has the ability to interact with c-Myc intracellularly.

\section{Results}

Deletion of a c-Myc amino-terminal region allows specific DNA binding by c-Myc alone

Using an Escherichia coli expression system, we produced a series of c-Myc proteins with progressively larger amino-terminal deletions. A polyhistidine tract fused to these Myc proteins permits single-step affinity purifica- tion by chromatography on a nickel-chelate column (Abate et al. 1990). Binding of these proteins to the DNA sequence GGGCACGTGCCC, a palindromic version of the c-Myc-binding site (Blackwell et al. 1990; Prendergast and Ziff 1991), was assayed by electrophoretic mobility-shift assay (EMSA) (Fig. 1A). Full-length Myc, as well as a truncated Myc lacking the amino-terminal 262 amino acids, could not bind to DNA (data not shown). However, deletion of the amino-terminal 317 amino acids (c-Myc 318-439) allowed weak specific DNA binding by c-Myc alone (Fig. 1A). Deletion of the amino-terminal 341 (c-Myc 342-439) or 349 amino acids (c-Myc 350-439) resulted in more potent DNA binding (Fig. 1A). Removal of the amino-terminal 366 amino acids (c-Myc 367-439), which include the basic region of $\mathrm{c}-\mathrm{Myc}$, resulted in a mutant protein that failed to bind to DNA (Fig. 1B). c-Myc 342-439 and c-Myc 350-439 bound DNA specifically, because nonradiolabeled GGGCACGTGCCC oligodeoxynucleotide, but not the oligo GGCCGCCCAAACTCAT, inhibited DNA binding competitively (Fig. 1B). Three independent monoclonal antibodies against the c-Myc zipper domain supershifted these specific protein-DNA complexes, indicating that $\mathrm{c}-\mathrm{Myc}$ is present in the complexes. The antibody preparations failed to bind DNA in the absence of c-Myc proteins, and a negative control antibody failed to supershift the DNA-protein complexes (Fig. 1C). We conclude that purified, bacterially produced c-Myc protein cannot bind DNA specifically unless the amino-terminal four-fifths of the protein, but not the basic region, is deleted.

\section{Sequence-specific DNA binding by purified recombinant Max protein alone and with $c-M y c$}

We expressed in $E$. coli a recombinant protein in which the Max amino acids 8-151 were fused to the polyhistidine tract as described above (Fig. 2A). The purified Max protein bound readily to the DNA sequence GACCACGTGGTC (Fig. 2B), a previously described c-Myc DNA-binding sequence (Halazonetis and Kandil 1991). Full-length bacterially produced c-Myc protein was partially purified by conventional column chromatography as described (Watt et al. 1985). The full-length c-Myc protein alone could not bind specifically to DNA alone, even at relatively high concentration $(5 \mu \mathrm{M})$. However, when full-length c-Myc and Max proteins were mixed and allowed to interact, they became capable of forming a new complex with DNA with a mobility slower than that of Max alone (Fig. 2B). We conclude that purified Max protein alone, but not c-Myc protein alone, is able to bind to the sequence GACCACGTGGTC. In addition, the mixture of full-length $\mathrm{c}-\mathrm{Myc}$ plus Max forms a protein-DNA complex of greater apparent molecular mass than that of Max alone. Immunoblots of the EMSA gels with anti-Max antiserum (a gift of E. Blackwood and R. Eisenman) confirm the presence of Max in the apparent c-Myc/Max complex (data not shown).

Max and c-Myc/Max complex bind to DNA in a dimeric protein structure

It has been hypothesized that HLH proteins bind to DNA 
A

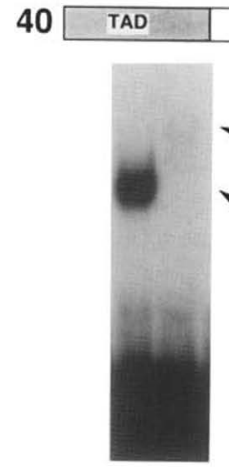

B

$\begin{array}{llllllllllll}1 & 2 & 3 & 4 & 5 & 6 & 7 & 8 & 9 & 10 & 11 & 12\end{array}$

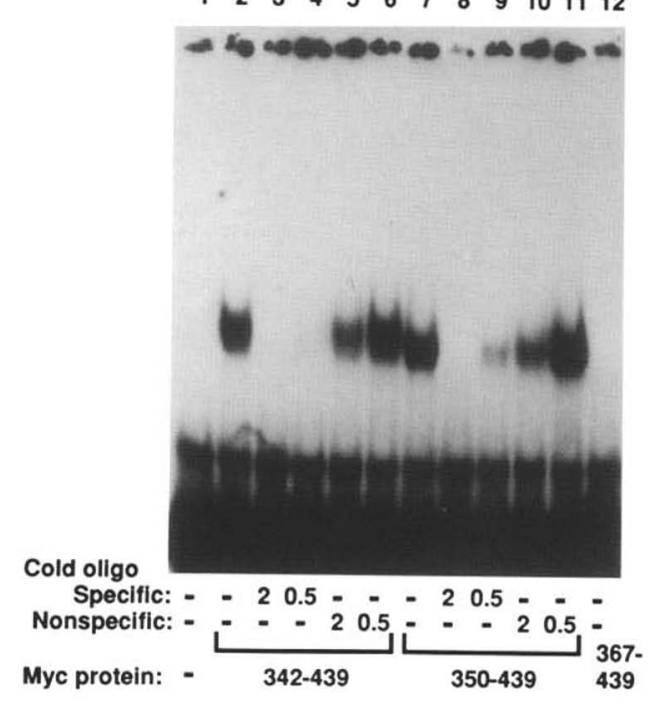

DNA

Binding 439

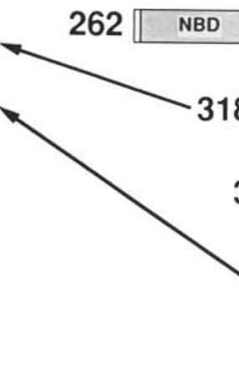

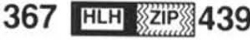

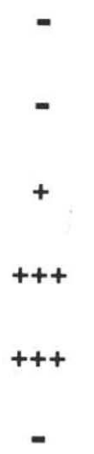

C

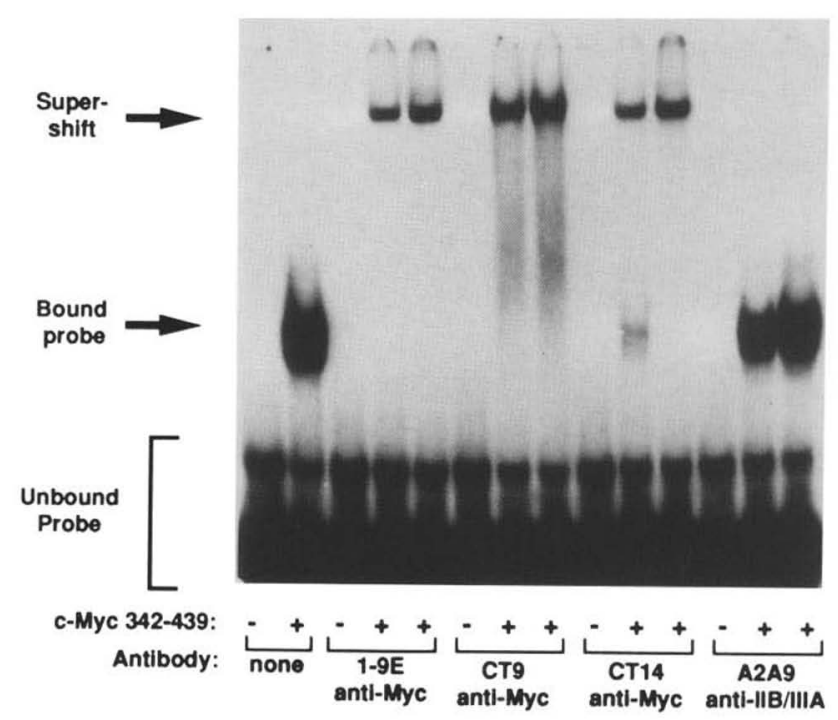

Figure 1. Amino-terminal truncation of the c-Myc protein allows specific DNA binding. $(A)$ Schematic depiction of truncated c-Myc proteins tested for the ability to bind specifically to the sequence GGGCACGTGCCC, with presence $(+)$ or absence $(-\mid)$ of DNAbinding ability indicated. (Inset) EMSA analysis of c-Myc(318-439) (left lane) and c-Myc(350-439) (right lane) using the same labeled oligodeoxynucleotide. $(B)$ Competition analysis by specific and nonspecific oligodeoxynucleotide. EMSA using radiolabeled GGGCACGTGCCC and no added protein (lane 1), c-Myc amino acids 342-439 (lanes 2-6), c-Myc amino acids 350-439 (lanes 7-11), and c-Myc amino acids 367-439 (lane 12) are shown. Nonradiolabeled oligodeoxynucleotides were added: GGGCACGTGCCC $2 \mu g$ (lanes 3,8), $0.5 \mu \mathrm{g}$ (lanes 4,9), or nonspecific oligodeoxynucleotide, $2 \mu \mathrm{g}$ (lanes 5,10), $0.5 \mu \mathrm{g}$ (lanes 6,11). (C) Supershift by anti-c-Myc antibodies. Mobility-shift analysis using GGGCACGTGCCC probe and no added c-Myc protein (lanes 1,3,6,9,12), c-Myc 341-439 protein (lanes 2,4,5,7,8,10,11,13,14) with added monoclonal antibodies against the c-Myc ZIP region 1-9E10 antibody (lanes 3-5), CT9 antibody (lanes 6-8), CT14 antibody (lanes 9-11), and A2A9 antibody against glycoprotein IIB/IIIA (lanes 12-14).

as homo- or heterodimers or tetramers, although physicochemical evidence supporting this hypothesis has been lacking. To investigate the DNA-bound oligomeric structures of Max and of Myc/Max complexes, we developed a novel strategy that we term the double-cross assay. In this assay, specific complexes of Max protein and the radiolabeled oligodeoxynucleotide GACCACGTGGTC were formed in the presence of excess unlabeled nonspecific DNA under conditions that yielded specific Max-DNA complexes by EMSA. The DNA was photocross-linked to Max protein by UV irradiation. Max protein was then chemically cross-linked in the presence of increasing concentrations of glutaraldehyde. The complexes subsequently were denatured under reducing conditions, resolved by SDS-PAGE, and detected by autoradiography (Fig. 2C). Max protein photo-cross-linked to DNA shows an apparent molecular mass of $22 \mathrm{kD}$, identical to that of purified Max. This mobility is altered to $44 \mathrm{kD}$ in the presence of glutaraldehyde induced protein-protein cross-linking, demonstrating that the predominant form of DNA-bound Max protein is a homodimer.

The double-cross assay was performed on complexes of the same DNA probe with Max protein plus excess 

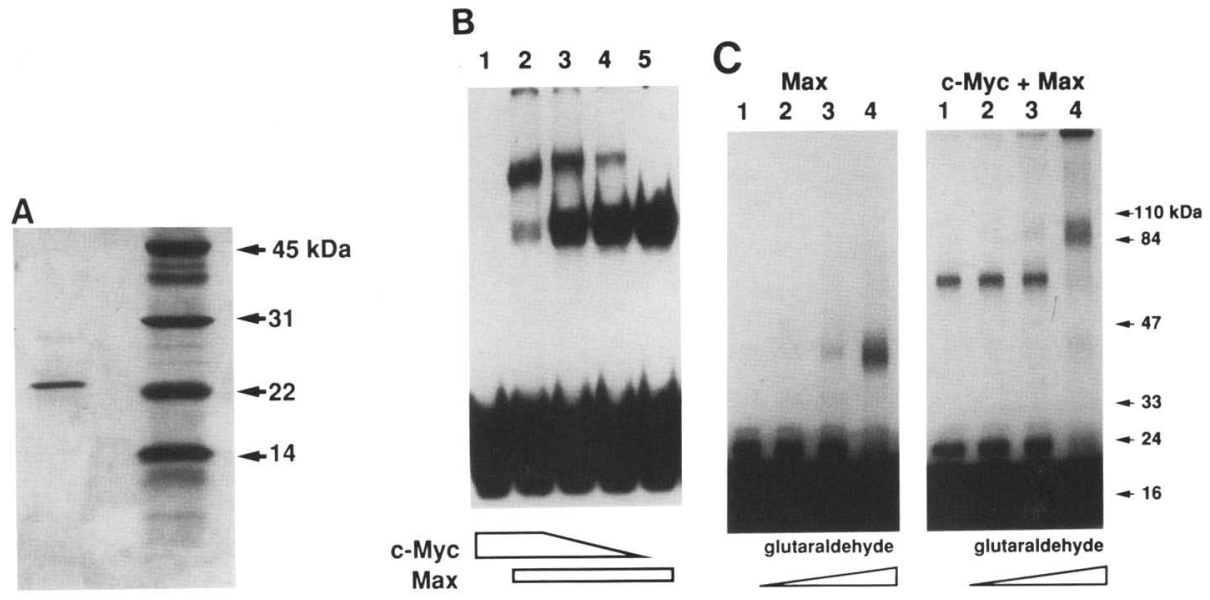

Figure 2. Specific DNA binding by the c-Myc/Max heteromeric complex. (A) SDS-PAGE analysis of purified Max protein (left lane), stained with Coomassie blue. Molecular mass markers are indicated in the right lane. $(B)$ Full-length c-Myc plus Max binds to DNA. EMSA using GACCACGTGGTC probe with varying amounts of bacterially produced c-Myc protein added to a fixed amount of Max protein. (Lanes 1,2) c-Myc $3 \mu \mathrm{g}$; (lane 3) $0.5 \mu \mathrm{g}$; (lane 4) $0.2 \mu \mathrm{g}$; (lanes 2-5) Max $0.05 \mu \mathrm{g}$. (C) Max and Myc/Max proteins bind to DNA as dimers. SDS-PAGE of Max protein (left) or c-Myc/Max protein (right) photo-cross-linked to GACCACGTGGTC probe with varying amounts of added glutaraldehyde: (Lane 1) 0\%, (lane 2) $0.01 \%$, (lane 3) $0.05 \%$, (lane 4) $0.25 \%$ glutaraldehyde. Positions of molecular mass markers are indicated at right.

purified full-length c-Myc protein. This Myc/Max mixture photo-cross-linked to DNA yielded two bands of similar intensity: one with apparent molecular mass of $22 \mathrm{kD}$, consistent with the expected mobility of Max; and one with apparent molecular mass of $65 \mathrm{kD}$, consistent with the mobility of c-Myc (Fig. 2C). Additional cross-linking with glutaraldehyde yielded a new $87-\mathrm{kD}$ band, suggestive of a summation of the molecular mass of Max cross-linked to c-Myc. We conclude that, in a heterodimeric complex, c-Myc and Max bind directly and specifically to the palindromic DNA sequence GACCACGTGGTC.

Sequence-specific DNA binding by truncated c-Myc, Max, or c-Myc/Max complexes

Truncated c-Myc protein presumably binds to the palindromic site CACGTG as a symmetrical homodimer, suggesting that each protein monomer might contact the half-site CAC. Although Max was also capable of binding to CACGTG, we hypothesized that a heteromeric complex of Max and c-Myc protein might prefer a different half-site that included the CA consensus for bHLH proteins. Therefore, we obtained synthetic oligodeoxynucleotides, each of which included two tandem repeats of the core sequences CACATG, CACCTG, CACGTG, or CACTTG. An oligodeoxynucleotide bearing two tandem repeats of the core sequence CAGCTG was used as a negative control. The DNA-binding preferences of truncated c-Myc, Max, and c-Myc/Max among these core sequence variants were determined by EMSA (Fig. 3). Truncated c-Myc protein bound specifically to CACGTG and CACATG. Max protein bound specifically to the same sequences, and bound very weakly to CACCTG and CACTTG. The c-Myc/Max complex also preferred CACGTG and CACATG. Binding to the CACGTG tandem repeat compared with a monomeric CACGTG site did not suggest a cooperative binding effect (data not shown), although this was not studied in detail and thus a cooperative effect cannot be ruled out. We conclude that Max, c-Myc, and the c-Myc/Max heterodimer share similar DNA core hexanucleotide-binding specificity.

\section{A nuclear localization signal in the carboxy-terminal region of Max}

The carboxy-terminal region of Max includes a basic re-
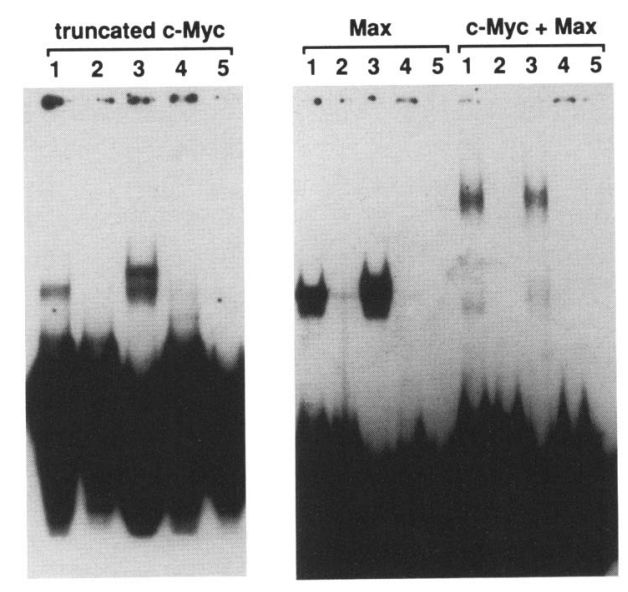

Figure 3. Effect of variation at the N position of the CACNTGbinding site on binding by c-Myc, Max, and c-Myc/Max. (Left) Truncated c-Myc protein; (center) Max protein; (right) c-Myc/ Max protein. (Lane 1) CACATG core sequence; (lane 2) CACCTG; (lane 3) CACGTG; (lane 4) CACTTG; (lane 5) CAGCTG. 
gion homologous to a number of nuclear localization signals (NLS) (Table 1) (for review, see Garcia-Bustos et al. 1991). We constructed chimeric genes that produce different regions of Max fused to chicken muscle pyruvate kinase (PK), a protein marker that normally is localized exclusively to the cytoplasm. The chimeric genes were transfected into COS-1 cells, and the intracellular location of the PK marker was detected by indirect immunofluorescence using anti-PK antiserum. Fusion of Max amino acids $1-126$ to $\mathrm{PK}$ failed to alter the cytoplasmic distribution of PK (Fig. 4). However, fusion of Max amino acids 126-151, which includes the putative NLS, directed complete nuclear localization of the PK marker. We conclude that the carboxy-terminal 23 amino acids of Max direct its nuclear localization; and by homology to known nuclear localization signals, this is most likely mediated by the peptide sequence PQSRKKLR.

\section{GAL4-Max fusion proteins fail to activate transcription in Chinese hamster ovary cells}

We constructed fusion genes that produce chimeric proteins of the DNA-binding domain (DBD) of the yeast transcriptional activator GAL4 linked to various regions of Max. Nearly full-length Max (amino acids 8-151), Max bHLH-ZlP domain (amino acids 8-103), and the carboxy-terminal region of Max (codons 102-151) were each separately linked to the GAL4 DBD (Fig. 5A). These constructs were transfected into Chinese hamster ovary $(\mathrm{CHO})$ cells and assayed for their ability to trans-activate a cotransfected reporter plasmid, G5E1bCAT, bearing five GAL4-binding sites and a minimal TATA box linked to a chloramphenicol acetyltransferase (CAT) gene. None of the Max fusion proteins was able to trans-activate the CAT gene above the background level of the unfused GAL4 DBD. A positive control construct of the

Table 1. Homology of the putative Max nuclear localization signal to the known NLS of other proteins

\begin{tabular}{|c|c|c|c|}
\hline PQS R & KKLR & & Max, human \\
\hline P A A & K R VK & LD & c-Myc, human \\
\hline P PQ & K K I K & $\mathrm{S}$ & N-Myc, human \\
\hline P L L & K K I K & $\mathrm{Q}$ & c-Myb, human \\
\hline P K & K K R K & VE & large $T$, SV40 \\
\hline P N & K K KR & K L & VP2, SV40 \\
\hline $\mathrm{P}$ & KQKR & $\mathrm{K}$ & NS1, influenza virus \\
\hline $\mathrm{P}$ & KKAR & ED & large $T$, polyoma virus \\
\hline S R & K R PR & $\mathrm{P}$ & large $T$, polyoma virus \\
\hline & K R PR & $\mathrm{P}$ & E1A, adenovirus \\
\hline G R & K K RR & QRRRAP & Tat, HIV \\
\hline GNKA & K RQR & & v-Rel, chicken \\
\hline GK & K R S K & A & histone $2 \mathrm{~B}$, yeast \\
\hline V & K KRK & $\mathrm{T}$ & N1, frog \\
\hline A & K K S K & QE & N1, frog \\
\hline $\mathrm{T}$ & K K RK & L E & lamin A, human \\
\hline $\mathrm{K}$ & K K KK & & c-Abl, murine \\
\hline $\mathrm{K}$ & K K I K & & glucocorticoid receptor, rat \\
\hline
\end{tabular}

Source: Garcia-Bustos et al. (1991).

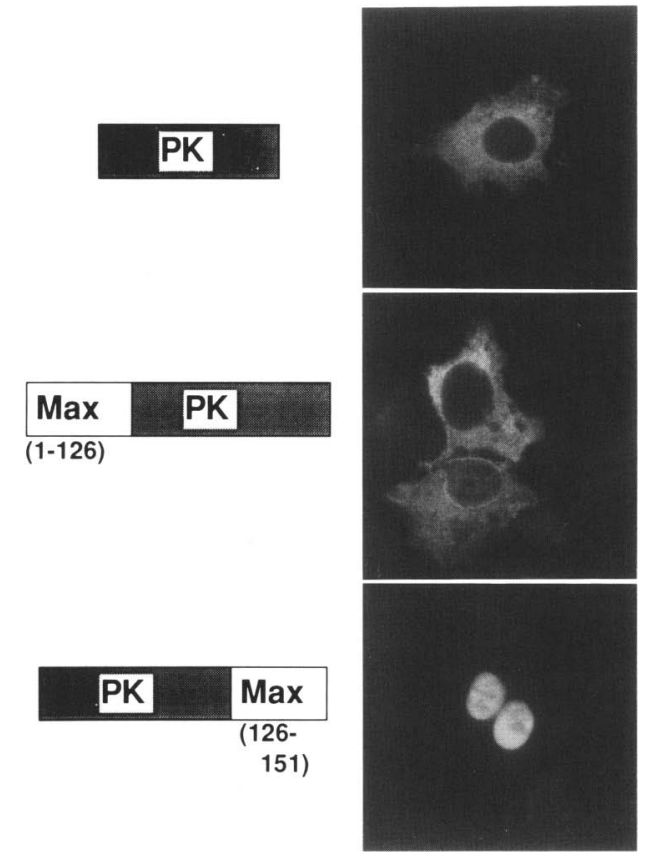

Figure 4. Nuclear localization signal of Max. (Left) Schematic depiction of PK fusion constructs used for each transfection. (Right) Fluorescent photomicrographs of COS-1 cells transfected with the indicated $\mathrm{PK}$ construct, and stained with rabbit anti-PK antiserum, followed by goat anti-rabbit antibody conjugated to rhodamine. (Top) Wild-type PK; (center) amino acids 1-126 of Max fused to PK; (bottom) PK fused to amino acids 126-151 of Max.

GAL4 DBD linked to the c-Myc transcriptional activation domain (TAD) stimulated CAT activity 145-fold over background (Fig. 5A). The Max fusion proteins were expressed at levels comparable to the GAL4-c-Myc fusion, as demonstrated by anti-GAL4 immunoprecipitation of transiently transfected $\mathrm{CHO}$ cells metabolically labeled with $\left[{ }^{35} \mathrm{~S}\right]$ methionine (Fig. 5B). This demonstrates that failure of the GAL4-Max fusions to transactivate is not the result of an absence of fusion protein expression. We conclude that in the context of a heterologous DBD, Max lacks a transcriptional activation domain that is active in CHO cells.

\section{Max associates with c-Myc intracellularly}

To determine the ability of the bHLH-ZIP domains of c-Myc and Max to interact in vivo, we used a previously described assay that detects intracellular protein-protein interactions (Fields and Song 1989; Dang et al. 1991). In this assay a functional transcriptional activator is reconstituted when compatible oligomerization domains link a chimeric protein bearing a DBD to another chimeric protein bearing a TAD. We constructed fusion genes that produce chimeric proteins with the bHLH-ZIP regions of c-Myc or Max fused to either the GAL4 DBD (DMyc and DMax) or to the TAD of the herpes simplex virus 
Kato et al.

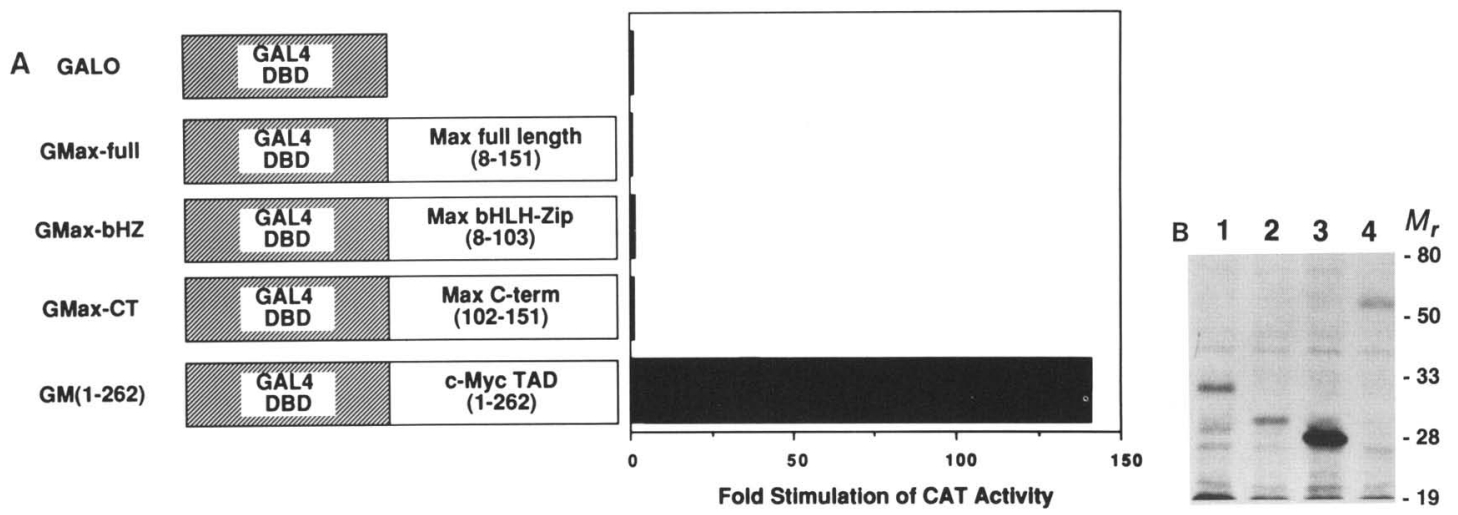

Figure 5. Lack of a transcriptional activation domain in Max. (A) Trans-activation studies. (Left) Schematic depiction of the DBD of GAL4 alone unfused or fused to Max codons 8-151, 8-103, 102-151, or c-Myc codons 1-262. (Right) Bar graph representing the relative CAT activity stimulated by each of the indicated GAL4 fusion genes when cotransfected with G5E1bCAT reporter plasmid into CHO cells. $(B)$ Immunoprecipitation of GAL4 fusion proteins. Autoradiograph of SDS-PAGE fractionation of proteins immunoprecipitated by anti-GAL4 antiserum following transient transfection of $\mathrm{CHO}$ cells and metabolic labeling with $\left[{ }^{35}\right.$ S $]$ methionine. (Lane 1) GMaxfull; (lane 2) GMax-bHZ; (lane 3) GMax-CT; (lane 4) GM(1-262). Positions of molecular mass markers (indicated in kD) are shown at right.

transcriptional activator VP16 (AMyc and AMax) (Fig. 6A). We transfected these plasmid constructs either alone or in various combinations into $\mathrm{CHO}$ cells along with the G5ElbCAT reporter plasmid. None of these fusions alone was able to trans-activate the CAT reporter gene (Fig. 6B). However, the bHLH-ZIP regions of c-Myc and Max interacted with each other to produce protein complexes that strongly trans-activated CAT; cotransfection of DMax and AMyc stimulated CAT activity 15-fold over background, and DMyc + AMax activated 9-fold over background (Fig. 6B). Deletion of the c-Myc HLH (AMycDH) or leucine zipper (AMycDZ) eliminated the ability to interact with DMax. Evidence of intracellular DMax-AMax association was equivocal, despite the fact that the DMax and AMax proteins each clearly were able to interact with the c-Myc fusions. We conclude that c-Myc and Max associate intracellularly.

\section{Discussion}

Our findings indicate that Max protein produced in $E$. coli binds DNA specifically and avidly. Previous studies have demonstrated that in vitro-translated human Max

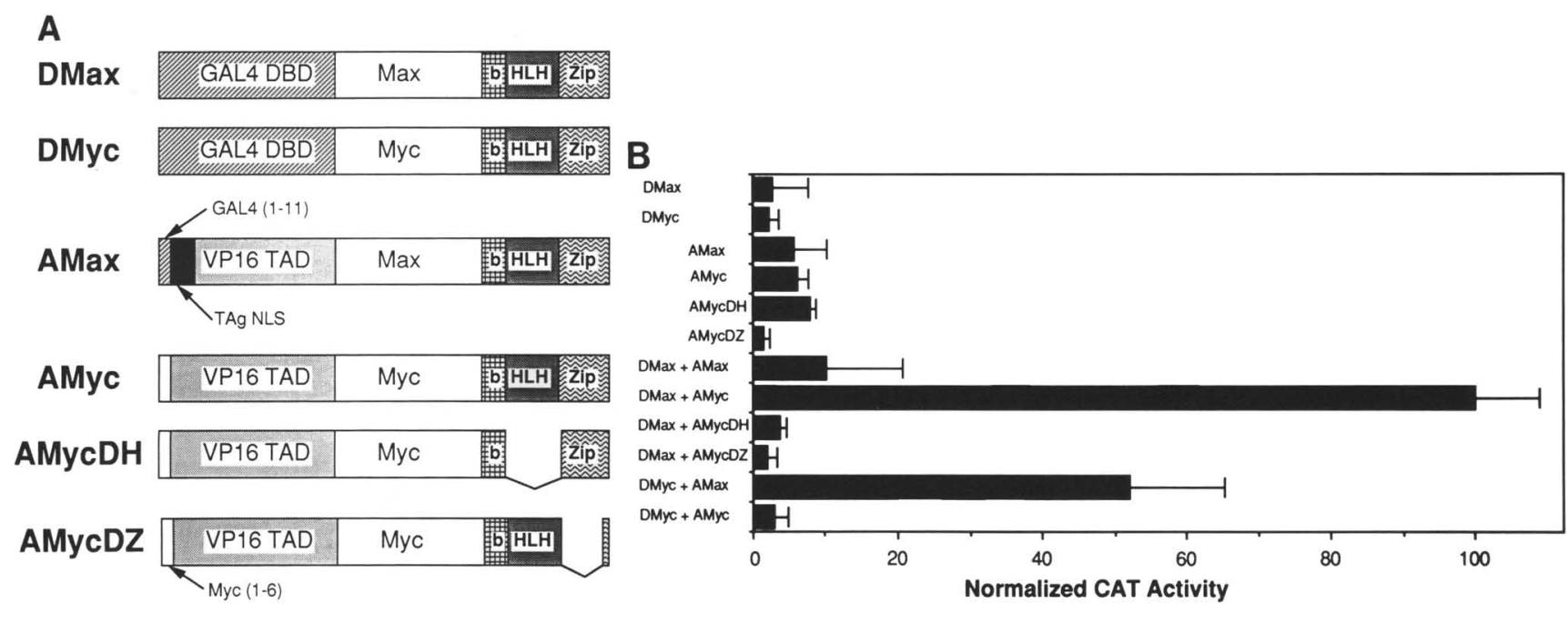

Figure 6. Intracellular interaction of c-Myc and Max. (A) Schematic depiction of constructs used, including fusions of the GAL4 DBD and of the VP16 TAD to Max codons 8-103 or c-Myc codons 262-439. AMax also includes GAL4 codons 1-11 and codons specifying the NLS of SV40 large T antigen. AMycDH bears a deletion of the HLH domain; AMycDZ bears a deletion of the leucine zipper domain. $(B)$ Bar graph representing normalized relative CAT activity stimulated by each construct alone and in combinations when cotransfected with G5ElbCAT reporter plasmid into CHO cells. Error bars represent the standard deviation derived from two to six assays of each construct or combination of constructs. 
does not bind DNA alone specifically (BIackwood and Eisenman 1991). In the case of Myn, the murine Max homolog, in vitro-translated protein binds to DNA weakly, and binding is greatly enhanced by deletion of the carboxy-terminal region, which includes consensus phosphorylation sites for casein kinase II. It is likely that post-translational phosphorylation by factors in the reticulocyte lysate inhibits DNA binding by Max or Myn, as suggested previously (Prendergast et al. 1991). This raises the important possibility that in vivo phosphorylation of amino acid residues in the carboxy-terminal region of Max may exert a regulatory control over Max DNA binding. It appears that phosphorylation at the amino-terminal region may exert such a control (S. Berberich and $\mathrm{M}$. Cole, pers. comm.). It is formally possible that our recombinant Max, in which the amino-terminal 7 amino acids are missing, may lack some domain inhibitory in vitro to dimerization or DNA binding, although this seems less likely.

Studies by others have demonstrated a peculiar pattern of specific DNA binding by c-Myc protein produced in vitro in rabbit reticulocyte lysate. Specifically, the EMSA mobility of the Myc-DNA complex was identical to that of the Myc/Max-DNA complex (Blackwood and Eisenman 1991; Prendergast et al. 1991). Others hypothesized that this property of Myc DNA binding is attributable to a unique physical property of the c-Myc polypeptide. However, one cannot exclude the possibility that the lysate might contain other Max-like factors that cooperate with c-Myc to bind DNA. In contrast, our data, obtained using recombinant c-Myc protein produced in E. coli, demonstrate that unmodified c-Myc protein is unable to bind to DNA in a sequence-specific fashion in the absence of another protein. Furthermore, our data indicate that a region in the amino-terminal four-fifths of c-Myc inhibits in vitro DNA binding by c-Myc alone but not by heterodimers of c-Myc and Max. We speculate that for the homodimeric c-Myc configuration, this region might sterically hinder either DNA contact or homodimerization, which is a prerequisite for specific DNA binding by $\mathrm{HLH}$ proteins. Comparable findings have been reported for the $\mathrm{v}-\mathrm{Myc}$ protein, in which amino-terminal truncation unmasks DNA-binding function and specifically the ability to bind the core sequence CACGTG (Kerhoff et al. 1991). A functionally similar region has been identified in the bHLH protein E12, in which an acidic region amino-terminal to the basic region inhibits DNA binding (Sun and Baltimore 1991). The possibility remains that the deleted forms of all of these Myc proteins might simply have artifactually altered characteristics, because an amino-terminal truncated murine c-Myc protein binds DNA less well than full length ( $M$. Cole, pers. comm.). In addition, the processes of bacterial expression and purification of the Myc proteins could conceivably cause loss of specific activity as a result of altered solubility, protein folding, or lack of post-translational modification. However, biological activity of our recombinant c-Myc protein preparation is demonstrated by its ability to bind DNA effectively as a heteromeric complex with Max. The specific activity of the full-length c-Myc preparation appears to be lower than that of the Max preparation; a 20-fold molar excess of Myc protein absorbs Max incompletely into active c-Myc/Max heterodimers (Fig. 2B).

The association of c-Myc with Max does not appreciably affect the recognition of the DNA core hexanucleotide CAC/G/A)TG as compared with either Max or truncated c-Myc alone, although Max can tolerate, to a small extent, more sequence variation at the $\mathrm{N}$ position of CACNTG. Our data corroborate previous evidence that the c-Myc/Max heterodimer binds to CACGTG (Blackwood and Eisenman 1991; Prendergast et al. 1991) and adds the new finding that the heterodimer additionally can bind CACATG, but not CACCTG nor CACTTG, when in a similar context of sequence flanking the core recognition hexanucleotide. None of these studies addresses the question whether Max might subtly influence DNA sequence preference at positions flanking the CAC(G/A)TG core hexanucleotide sequence. The importance of such flanking residues to sequence-specific binding by truncated c-Myc has been demonstrated (Halazonetis and Kandil 1991). Identification of an optimal binding site including these flanking residues remains to be performed systematically for truncated c-Myc, Max, and c-Myc/Max heterodimer.

Max and c-Myc are examples of the bHLH-ZIP proteins. The interaction of c-Myc with Max is dependent on the integrity of both HLH and ZIP (Blackwood and Eisenman 1991). The HLH domain lies adjacent to a region rich in basic residues that appears to contact DNA directly and contributes to the specificity of DNA sequence recognition (Murre et al. 1989). A number of studies have indicated that oligomerization is a prerequisite for DNA binding by bHLH proteins (Murre et al. 1989; Voronova and Baltimore 1990). However, previously published data have not documented the stoichiometry of this interaction with respect to DNA binding. In particular, because bHLH-ZIP proteins have two potential oligomerization motifs, the possibility exists that they may bind DNA in higher order oligomers such as tetramers, although this was not seen for cross-linking studies in solution without DNA for bHLH-ZIP proteins TFE3 (Beckmann and Kadesch 1991) and AP4 (Hu et al. 1990). Data derived from simple UV photo-cross-linking of DNA-protein complexes may be misleading in some cases; such data led to the initial impression that the bHLH-ZIP protein USF could bind to DNA as a monomer (Sawadogo 1988). Only molecular cloning of USF and analysis of truncation mutants led to the conclusion that upstream stimulatory factor (USF) binds DNA in dimers or higher order oligomers (Gregor et al. 1990).

In this report we describe a novel technique, the double-cross assay, that provides direct physicochemical evidence for the oligomerization state of DNA-bound protein. After photo-cross-linking of the proteins to a radiolabeled oligodeoxynucleotide probe, protein gel electrophoresis under denaturing conditions establishes the apparent molecular mass of the proteins, which directly contact the DNA probe. Glutaraldehyde cross-linking of protein-protein interactions in the second step 
allows identification of a new species whose apparent molecular mass is a summation of the apparent molecular masses of each of the components of the DNAprotein complex. For Max, the primary photo-cross-linking step resulted in Max bands of $22 \mathrm{kD}$. The secondary protein-protein cross-linking step then produced a 44$\mathrm{kD}$ band, equivalent to two cross-linked molecules of Max, demonstrating that Max binds to DNA as a dimer. This demonstrates that Max binds to a single palindromic DNA site predominantly as a homodimer and not as monomers, tetramers, or higher order oligomers.

Similarly, the first cross-linking step for c-Myc-Max complex yielded bands of 65 and $22 \mathrm{kD}$, consistent with c-Myc and Max, respectively. The second step yielded an $87-\mathrm{kD}$ band, consistent with the summation of one molecule each of c-Myc and Max in a DNA-bound protein complex. Thus, c-Myc/Max binds DNA predominantly as a heterodimer and not as higher order oligomers, although minor bands of slower mobility are notable. It is not clear whether the faint slower mobility band may represent a higher order complex. At increased concentrations of glutaraldehyde, all samples form high-molecular-mass aggregates of questionable significance /data not shown). It is appropriate to caution that we have not demonstrated conclusively that the double-cross assay in general can detect bona fide DNA-bound tetramers.

Our data from the double-cross assay provide physicochemical evidence that a dimeric structure is the predominant form involved in DNA binding for the Max homodimer and the c-Myc/Max heterodimer, and that each subunit of the dimer contacts DNA directly. Extrapolation from these findings suggests that in general, bHLH and bHLH-ZIP proteins bind to DNA virtually exclusively in a dimeric structure. The double-cross assay may be of broad utility to establish the DNA-bound oligomer status for other DNA-binding proteins.

The c-Myc protein possesses a domain that is capable of activating transcription of a reporter gene when bound to DNA by a heterologous DNA-binding domain. This domain maps to a region of the protein that is required for the transforming ability of c-Myc (Kato et al. 1990). Thus, Max need not have a similar TAD for the c-Myc/ Max heterodimer to function as a transcriptional activator. Our data suggest that Max does not have a functional $\mathrm{TAD}$, despite the presence of a small acidic region near its carboxyl terminus. This finding is consistent with the demonstration that deletions in the TAD of c-Myc block its ability to transform rat embryo fibroblasts (Sarid et al. 1987; Stone et al. 1987), suggesting that Max does not have a functional TAD to complement c-Myc TAD mutations when $\mathrm{c}-\mathrm{Myc} / \mathrm{Max}$ heterodimers are formed in vivo. This may explain why a c-Myc TAD mutation behaves transdominantly to block c-Myc-induced transformation (Dang et al. 1989b). Although it is possible that Max might have trans-activation properties in different cell lines or tissues, the lack of transcriptional activation by Max is consistent with its hypothesized role as a positively acting cofactor for c-Myc function and a potentially negatively acting transcription factor in the absence of c-Myc (Cole 1991). Our GAL4-Max fusions did not include the amino-terminal 7 amino acids of Max. However, similar studies with other GAL4-Max constructs, which include all but the initiating methionine of Max, confirm the lack of a Max activation domain independently (E. Prochownik, pers. comm.). We did not specifically investigate whether Max has a transcriptional suppressor domain.

Because Max can homodimerize with itself and heterodimerize with $\mathrm{c}-\mathrm{Myc}$, we sought to determine whether Max contains a potential nuclear localization signal that would allow rapid nuclear entry of Max homodimers. The c-Myc protein has been shown to possess a peptide sequence that is responsible for its nuclear localization (Dang and Lee 1988). If this peptide is linked to a normally cytoplasmic marker protein, the marker protein then localizes to the nucleus. Because there is precedent that proteins with an NLS may bind to other proteins and carry them into the nucleus (Dang et al. 1991), it is possible that c-Myc might carry Max into the nucleus in the absence of a Max NLS. Furthermore, the relatively small size of a Max monomer theoretically would allow its entry into the nucleus by passive diffusion, although a Max dimer would be too large to enter passively (Dingwall and Laskey 1986). However, to act efficiently as an independent transcription factor, Max ought to have independent nuclear localization function. Our data demonstrate that a peptide sequence in the carboxy-terminal 23 amino acids can function as an efficient NLS. It is very likely that the NLS in this region is PQSRKKLR, which resembles the c-Myc NLS and conforms to the lysine-basic-X-basic consensus for many NLS (Garcia-Bustos et al. 1991), along with the frequent occurrence of an adjacent helix-breaking amino acid such as proline (Table 1). Additional data have demonstrated that wild-type Myn, the murine Max protein, is localized in the nucleus and that a mutation in the putative NLS, PQSRKKLR, diminishes the efficiency of nuclear targeting (G. Prendergast and E. Ziff, pers. comm.).

Ample evidence has been presented previously that Max interacts specifically with c-Myc in solution in vitro (Blackwood and Eisenman 1991; Prendergast et al. 1991). However, to date, no intracellular association of the two proteins has been documented. Using an intracellular association assay, we could not detect c-Myc homo-oligomerization intracellularly (Dang et al. 1991). In this same assay, we have shown that the HLH-ZIP region of Max interacts with the corresponding region of c-Myc intracellularly, providing further evidence that Max is a physiological partner protein for c-Myc function. This interaction is dependent, as expected, on the integrity of both the HLH and the ZIP domains of c-Myc, and presumably on those of Max as well. Expression of each of the fusion constructs, except for the c-Myc deletion mutants, is demonstrated functionally by its ability to interact intracellularly to activate transcription of CAT.

Interestingly, the Max chimeric proteins, which interact well with the c-Myc chimeras, fail to interact strongly with each other intracellularly. This observation raises the question whether Max forms homodimers 
physiologically in vivo, despite the in vitro homodimerization data. It has been observed that high levels of a cotransfected Max expression plasmid can inhibit c-Myc/Ras cotransformation of rat embryo cells, implying that Max may homodimerize in vivo to act as a suppressor at C-Myc/Max DNA-binding sites (J. Barrett and C. Dang, unpubl.; G. Prendergast and E. Ziff, pers. comm.). Despite its specificity, the intracellular proteinprotein interaction assay may not be highly sensitive, as it has failed to detect c-Jun homodimerization (Dang et al. 1991). Furthermore, increased DNA binding by in vitro-translated Myn has been observed with a carboxyterminal deletion that is 9 amino acids greater than that used for our intracellular assay (Prendergast et al. 1991). It is possible that post-translational modification within this nonapeptide sequence is sufficient to suppress Max homodimerization intracellularly. This nonapeptide sequence, KARSSAQLQ, includes a consensus site for potential phosphorylation by cAMP-dependent protein $\mathrm{ki}$ nase (Kennelly and Krebs 1991).

The current studies deal with the 151-amino-acid form of Max and, in some cases, with a slightly truncated form lacking the amino-terminal 7 amino acids. We did not evaluate the 160-amino-acid product of an alternatively spliced transcript, which has 9 additional amino acids in the amino-terminal region. It is possible that the longer form of Max might differ in its biological activity, although this issue remains to be studied.

The data that have accumulated to date are consistent with the following model (Fig. 7): Max is specifically transported to the nucleus, where it may exist as a homodimer, and it acts to suppress transcription at DNA sequences related to $\mathrm{CAC} / \mathrm{G} / \mathrm{A}) \mathrm{TG}$. This binding may be regulated by phosphorylation at as yet unknown sites, including a potential carboxy-terminal casein kinase II phosphorylation site. Induced regulated high-level c-Myc expression, resulting in $\mathrm{c}-\mathrm{Myc} / \mathrm{Max}$ heterodimers binding to $\mathrm{CAC}(\mathrm{G} / \mathrm{A}) \mathrm{TG}$, could transiently activate transcription of growth-promoting genes, and also could possibly inhibit transcription of growth suppression genes. In contrast, deregulated c-Myc expression, leading to continuous formation of c-Myc/Max heterodimer, could promote neoplastic cell proliferation. Support for such a model awaits direct evidence of transcriptional regulation of specific growth-related genes by the c-Myc/Max heterodimer.

\section{Materials and methods}

E. coli expression plasmids

All plasmids were constructed and manipulated by use of standard techniques (Sambrook et al. 1989). The E. coli expression vector pDS56-6xHis (a gift from F. Rauscher), containing an ATG start codon followed by 6 histidine codons, was modified to create downstream $\mathrm{ClaI}$ and $\mathrm{XhoI}$ sites. XhoI-Nsil fragments of various c-myc deletion mutants (Stone et al. 1987) were subcloned between the XhoI and PstI sites of the modified vector, giving rise to a pDS-Myc series of plasmids. The modified pDS65-6xHis vector was modified further to include an NsiI site, and between the ClaI and NsiI sites a max fragment was inserted from the upstream TaqI site to the NsiI site from pVZ1p21Max, a plasmid that encodes the shorter 151-aminoacid Max polypeptide la gift from E. Blackwood and R. Eisenman), generating the new plasmid pDS-Max. The PRMyc expression vector that encodes full-length c-Myc la gift from R. Watts) has been described previously (Watt et al. 1985).

\section{PK fusion plasmids}

The PK expression plasmid RLPK 12 has been described previously (Kalderon et al. 1984). The max SstI-TaqI fragment with codons $1-126$ of pVZ1p21Max was subcloned into pGALO (Kato et al. 1990) between the SstI and ClaI sites to acquire a new downstream XhoI site. The SstI-XhoI fragment from the resulting plasmid pGRMax(1-126) was subcloned, in turn, along with the HindIII-SstI fragment from pBluescript II KS - ) (Stratagene), into pMycl05PK (Dang and Lee 1988) between its HindIII and XhoI sites, resulting in plasmid pMax126PK. The max TaqI-EcoRI fragment with codons 126-151 of pVZ1p21Max was subcloned between the ClaI and EcoRI sites of pBluescript II KS $(-1$, creating pBMax(126-151). The max fragment was cleaved from this plasmid with $\mathrm{XhoI}$ and $\mathrm{BamHI}$, and subcloned, in turn, into pPK350Myc between its XhoI and BglII sites, resulting in plasmid pPK126Max.

\section{GAL4 DBD fusion plasmids}

The GAL4-Myc fusion plasmids GM(1-262) and GM(262-439) and vectors GALO and GALM have been described previously (Kato et al. 1990). All constructs contain the SV40 early promoter upstream from the DBD and NLS encoded by GAL4 codons 1-147 (Sadowski et al. 1988). Plasmid pGMax-bHZ was created by three-piece ligation of the 311-bp TaqI-Pst I fragment of pVZlp21Max, including Max codons $8-103$ to the $1.5-\mathrm{kb}$ PstI-ClaI fragment of GALO and the 1.9-kb PstI fragment of

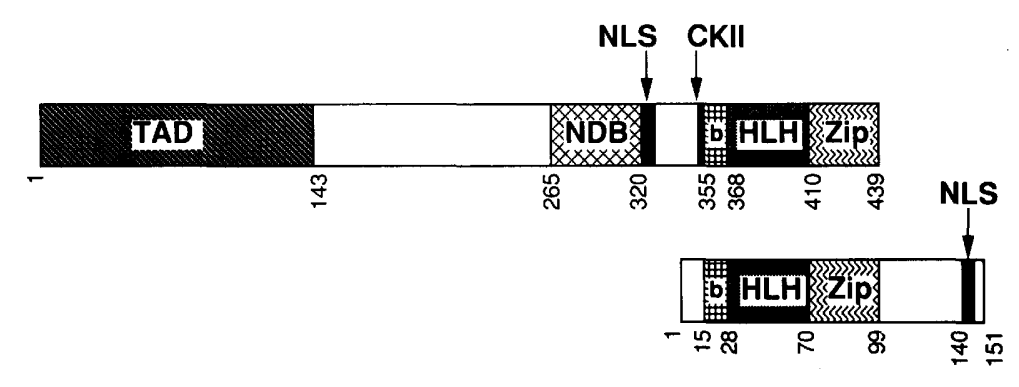

Figure 7. Functional domains of c-Myc and Max. Summary of functional activities that have been mapped definitively to indicated regions of the c-Myc or Max protein: transcriptional activation domain (TAD); nonspecific DNA-binding domain (NDB); nuclear localization signal (NLS); casein kinase II phosphorylation site (CKII) (Lüscher et al. 1989); basic specific DNA-binding domain (b); helix-loop-helix and leucine zipper oligomerization domains (HLH-ZIP). The top bar represents the c-Myc protein; the bottom bar represents the 151amino-acid Max protein. The codons that lie at the border of each domain are indicated below the bars. 
GALM. Plasmid pGMax-CT was constructed by three-piece ligation of the 150-bp PstI-EcoRI fragment of pVZ1p21Max, including Max codons $102-151$ to the $1.5-\mathrm{kb}$ Pst fragment of GALM and the 1.9-kb PstI-EcoRI fragment of GALO. Plasmid pGMax-full was constructed by three-piece ligation of the 0.9 $\mathrm{kb}$ HindIII-PstI fragment of pGMax-bHZ to the 210-bp PstI$X b a \mathrm{I}$ and $2.5-\mathrm{kb} \mathrm{XbaI-HindIII}$ fragments of pGMax-CT. DMax is identical to pGMax-bHZ, and DMyc is identical to GM/262439). The reporter plasmid G5E1bCAT has been described previously (Lillie and Green 1989).

\section{VP16 TAD fusion plasmids}

All Myc-VP16 fusions include the TAD encoded by codons 411-490 of VP16. AMyc has been described previously and includes the NLS and bHLH-ZIP regions encoded by c-Myc codons 262-439 (Dang et al. 1991). AMycDH, containing a deletion of the HLH region encoded by c-Myc codons 371-412, was generated by three-piece ligation of the 280-bp SalI-ClaI fragment of pBVPA490 (Dang et al. 1991) to the 3.2-kb XhoIHindIII fragment of pMLVMycIn6 (Stone et al. 1987) and the 4.0-kb ClaI-HindIII fragment of pMLVMyc $\Delta 371-412$ (Stone et al. 1987). AMycDZ, containing a deletion of c-Myc codons 413433 in the ZIP region, was constructed similarly, using the 4.0 $\mathrm{kb} \mathrm{ClaI-HindIII} \mathrm{fragment} \mathrm{of} \mathrm{pMLVMyc} \Delta 413-433$ (Stone et al. 1987). AMax was constructed by ligation of the 350-bp SalI$\mathrm{XbaI}$ fragment of pGMax-bHZ between the sames sites in $\mathrm{pN}$ LVP, a eukaryotic expression vector that encodes the aminoterminal 11 amino acids of GAL4 fused to the SV40 large T antigen NLS PKKKRKVD, followed by the VP16 TAD codons 411-455, followed by a multiple cloning site (Dang et a. 1991). All constructs contain the promoter region of the Moloney murine leukemia virus, except for AMax, which contains the SV40 early promoter.

\section{Synthetic oligodeoxynucleotides}

The oligodeoxynucleotides listed in Table 2 were synthesized by the Oligonucleotide and Peptide Synthesis Facility at the Johns Hopkins University School of Medicine, by Oligos Etc., Inc. (Guilford, CT), or on an Applied Biosystems PCR-Mate oligonucleotide synthesizer.

\section{Protein preparation}

Full-length c-Myc protein was prepared and purified as described (Watt et al. 1985) to a purity of $\sim 50 \%$ as estimated by gel electrophoresis (data not shown). The truncated c-Myc proteins and the Max protein were prepared and purified as described (Abate et al. 1990). The proteins were stored in $10 \mathrm{~mm}$ Tris- $\mathrm{HCl}$ (pH 7.4), $100 \mathrm{mM} \mathrm{NaCl}, 1 \mathrm{~mm}$ EDTA $\cdot \mathrm{Na}_{2}, 1 \mathrm{~mm}$ dithiothreitol (DTT), and $10 \%$ glycerol in aliquots at $-85^{\circ} \mathrm{C}$.

\section{SDS-PAGE}

SDS-PAGE was performed under reducing conditions by standard methods (Sambrook et al. 1989). Purified Max protein was resolved on a $15 \%$ polyacrylamide slab gel with $37.5: 1$ acrylamide/bis-acrylamide and stained with Coomassie blue. Crosslinked proteins were resolved on a $10 \%$ polyacrylamide gel.

\section{EMSA}

DNA probes were prepared by filling $5^{\prime}$ overhangs with the Klenow fragment of DNA polymerase I (Pharmacia) and $\left[\alpha^{-32} \mathrm{P}\right] \mathrm{dCTP}$ (Amersham) along with nonradioactive dATP,
Table 2. Synthetic oligonucleotides

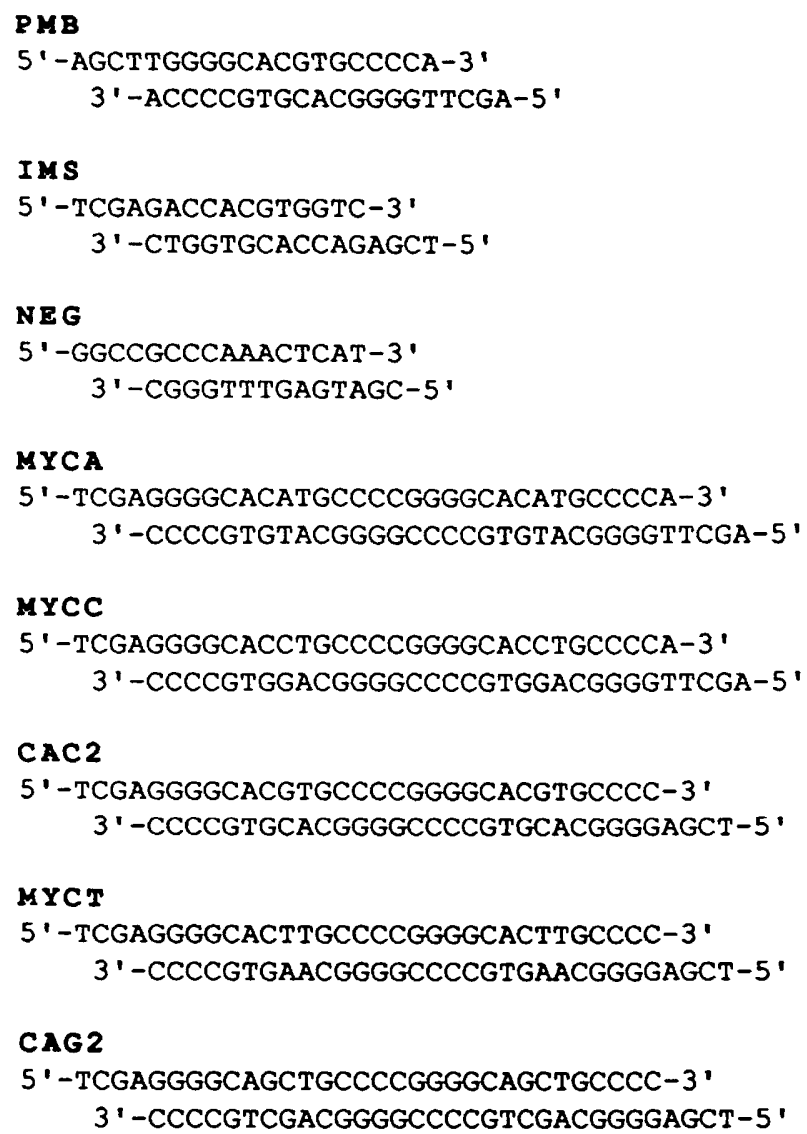

dGTP, and dTTP (Pharmacia), achieving a specific activity of $10^{5}-10^{6} \mathrm{cpm} / \mathrm{pmole}$. Approximately $50 \mathrm{ng}$ of Max protein or up to $6 \mu \mathrm{g}$ of Myc protein was added to $1 \mu \mathrm{g}$ of poly[d(I-C)] (Pharmacia) in $10 \mathrm{~mm}$ Tris- $\mathrm{HCl}(\mathrm{pH} 7.4), 80 \mathrm{~mm} \mathrm{NaCl}, 1 \mathrm{~mm}$ DTT, and $5 \%$ glycerol in a final volume of $10-20 \mu \mathrm{l}$. In the case of heterodimer formation, this mixture first was warmed to $42^{\circ} \mathrm{C}$ for $15 \mathrm{~min}$ to allow dimer exchange. All reactions were then incubated for $15 \mathrm{~min}$ at room temperature, followed by the addition of $1 \times 10^{5}$ to $5 \times 10^{5} \mathrm{cpm}$ of probe to each reaction. After $15 \mathrm{~min}$ at room temperature, $3 \mu \mathrm{l}$ of $0.1 \%$ bromophenol blue in the same buffer was added, and the mixtures were electrophoresed on a $5 \%$ polyacrylamide gel $(37.5: 1$ acrylamide/bis-acrylamide) in 0.5 $\times$ TBE buffer (Sambrook et al. 1989), with $0.01 \%$ NP-40 (Sigma) that had been prerun at $20 \mathrm{~V} / \mathrm{cm}$ for $30 \mathrm{~min}$. Following electrophoresis at $20 \mathrm{~V} / \mathrm{cm}$, the gel was dried and subjected to autoradiography for 3-72 hr. For assessment of the comparative DNA-binding potential of the various truncated c-Myc proteins, protein concentrations were determined by the Bradford assay and protein purities were estimated by SDSPAGE and Coomassie blue staining. Quantities were then adjusted to yield equimolar amounts of the various c-Myc proteins as assessed by inspection of an immunoblot of the preparations developed with the 9E10 monoclonal antibody directed against the c-Myc carboxyl terminus (Evan et al. 1985), followed by anti-murine IgG conjugated to horseradish peroxidase. Quantities of the proteins corresponded to an amount equimolar to 1 $\mu \mathrm{g}$ of of $\mathrm{c}-\mathrm{Myc}(354-439)$. 
Supershift assays were run as described above, with $1 \mu$ of monoclonal antibody added at the beginning of the first incubation. Antibodies were anti-Myc 9E10, CT-9, CT-14 (Evan et al. 1985), or anti-glycoprotein IIB/IIIA (Bennett et al. 1983).

\section{Double-cross assay}

DNA-binding reactions were assembled similar to the above EMSA assays in $1.5-\mathrm{ml}$ microcentrifuge tubes. The tubes were placed directly on a short wavelength UV light table (Fotodyne) and were directly irradiated for $30 \mathrm{~min}$. Glutaraldehyde (Polysciences) was added to varying final concentrations of $0.01-$ $0.25 \%$, and the reactions were incubated at room temperature for $20 \mathrm{~min}$. This high concentration of glutaraldehyde was required to overcome chemical inactivation of glutaraldehyde by the DTT present in the protein storage buffer, producing inactive mercaptal adducts. An equal volume of $2 \times$ Laemmli reducing SDS-loading buffer was added to each tube, and the samples were heated to $100^{\circ} \mathrm{C}$ for $10 \mathrm{~min}$ and fractionated by SDS-PAGE. The gel was dried and subjected to autoradiography for $24 \mathrm{hr}$.

\section{Transcriptional activation and intracellular interaction} assays

DUKXBII CHO cells were maintained and transfected by the DEAE-dextran technique as described (Lillie and Green 1989; Dang et al. 1991). CAT activity was assayed by the phase extraction method using $\left[{ }^{14} \mathrm{C}\right]$ chloramphenicol (Amersham) as described (Seed and Sheen 1988; Dang et al. 1991). In the case of assays for a potential Max activation domain, transfection efficiency was evaluated by cotransfection with $2 \mu \mathrm{g}$ of pCH110 (Pharmacia), a $\beta$-galactosidase constitutive expression plasmid, and enzyme activity was assayed (Sambrook et al. 1989). The range of variation in transfection efficiency was less than threefold (data not shown). Each construct was tested in two to six transfections. Immunoprecipitation analysis was performed from transfected CHO cells, using anti-GAL4 antiserum (gift of I. Sadowski), as described previously (Kato et al. 1990).

\section{Nuclear localization studies}

COS-1 cells were maintained and transfected in a manner similar to that described for COS-7 cells, except that chloroquine was added to a final concentration of $0.1 \mathrm{~mm}$ during the $5-\mathrm{hr}$ DEAE-dextran transfection, and subsequent indirect immunofluorescence was performed as described (Dang and Lee 1988).

\section{Acknowledgments}

This work was supported in part by National Institutes of Health (NIH) grants CA51497 and T32HL07525, by the Henry M. and Lillian Stratton Foundation, Inc., and by a Hubert and Anne E. Rogers Scholarship. G.J.K. is supported in part by the NIH Child Health Research Center Grant (p 30HD27799) and is a recipient of an American Society of Clinical Oncology Young Investigator Award. W.M.F.L. is supported in part by the W.W. Smith Charitable Trust. C.V.D. holds an American Cancer Society Junior Faculty Research Award (JFRA-281). We are grateful to John Barrett for superb technical support. We are indebted to Beth Blackwood and Bob Eisenman for gifts of the Max cDNA plasmid and anti-Max antiserum, to Jim Lillie and Ivan Sadowski for GAL4 plasmids and anti-GAL4 antiserum, to Frank Rauscher and Tom Curran for pDS56-6xHis E. coli expression system, to George Prendergast and Ed Prochownik for helpful discussions, and to Michael Cole for critically reviewing the manuscript.
The publication costs of this article were defrayed in part by payment of page charges. This article must therefore be hereby marked "advertisement" in accordance with 18 USC section 1734 solely to indicate this fact.

\section{References}

Abate, C., D. Luk, R. Gentz, F.J. Rauscher III, and T. Curran. 1990. Expression and purification of the leucine zipper and DNA-binding domains of Fos and Jun: Both Fos and Jun contact DNA directly. Proc. Nat1. Acad. Sci. 87: 1032-1036.

Beckmann, H. and T. Kadesch. 1991. The leucine zipper of TFE3 dictates helix-loop-helix dimerization specificity. Genes \& Dev. 5: 1057-1066.

Bennett, J.S., J.A. Hoxie, S.F. Leitman, G. Vilaire, and D.B. Cines. 1983. Inhibition of fibrinogen binding to stimulated human platelets by a monoclonal antibody. Proc. Natl. Acad. Sci. 80: 2417-2421.

Blackwell, T.K., L. Kretzner, E.M. Blackwood, R.N. Eisenman, and $H$. Weintraub. 1990. Sequence-specific DNA binding by the c-Myc protein. Science 250: 1149-1151.

Blackwood, E.M. and R.N. Eisenman. 1991. Max: A helix-loophelix zipper protein that forms a sequence-specific DNAbinding complex with Myc. Science 251: 1211-1217.

Cole, M.D. 1991. Myc meets its Max. Cell 65: 715-716.

Dang, C.V. and W.M.F. Lee. 1988. Identification of the human c-myc protein nuclear translocation signal. Mol. Cell. Biol. 8: 4084-4054.

Dang, C.V., H. van Dam, M. Buckmire, and W.M.F. Lee. 1989a. DNA-binding domain of human c-Myc produced in Escherichia coli. Mol. Cell. Biol. 9: 2477-2486.

Dang, C.V., M. McGuire, M. Buckmire, and W.M.F. Lee. 1989b. Involvement of the leucine zipper region in the oligomerization and transforming activity of human c-myc protein. $\mathrm{Na}$ ture 337: 664-666.

Dang, C.V., J. Barrett, M. Villa-Garcia, L.M.S. Resar, G.J. Kato, and E.R. Fearon. 1991. Intracellular leucine zipper interactions suggest c-Myc hetero-oligomerization. Mol. Cell. Biol. 11: 954-962.

Dingwall, C. and R.A. Laskey. 1986. Protein import into the cell nucleus. Annu. Rev. Cell Biol. 2: 367-390.

Evan, G.I., G.K. Lewis, G. Ramsay, and J.M. Bishop. 1985. Isolation of monoclonal antibodies specific for the human c-myc proto-oncogene product. Mol. Cell. Biol. 5: 36103616.

Fields, S. and O. Song. 1989. A novel genetic system to detect protein-protein interactions. Nature 340: 245-246.

Garcia-Bustos, J., J. Heitman, and M.N. Hall. 1991. Nuclear protein localization. Biochim. Biophys. Acta 1071: 83-101.

Gregor, P.D., M. Sawadogo, and R.G. Roeder. 1990. The adenovirus major late transcription factor USF is a member of the helix-loop-helix group of regulatory proteins and binds to DNA as a dimer. Genes \& Dev. 4: 1730-1740.

Halazonetis, T.D. and A.N. Kandil. 1991. Determination of the c-Myc DNA-binding site. Proc. Natl. Acad. Sci. 88: 61626166.

Hu, Y.F., B. Luscher, A. Admon, N. Mermod, and R. Tjian. 1990. Transcription factor AP-4 contains multiple dimerization domains that confer dimerization specificity. Genes \& Dev. 4: 1741-1752.

Kalderon, D., B.L. Roberts, W.D. Richardson, and A.E. Smith. 1984. A short amino acid sequence able to specify nuclear location. Cell 39: 499-509.

Kato, G.J., J. Barrett, M. Villa-Garcia, and C.V. Dang. 1990. An amino-terminal domain of c-Myc required for transforma- 
tion activates transcription. Mol. Cell. Biol. 10: 5914-5920.

Kennelly, P.J. and E.G. Krebs. 1991. Consensus sequences as substrate specificity determinants for protein kinases and protein phosphatases. J. Biol. Chem. 266: 15555-15558.

Kerhoff, E., K. Bister, and K.H. Klempnauer. 1991. Sequencespecific DNA binding by Myc proteins. Proc. Natl. Acad. Sci. 88: 4323-4327.

Lillie, J.W. and M.R. Green. 1989. Transcription activation by the adenovirus Ela protein. Nature 338: $39-44$.

Lüscher, B. and R.N. Eisenman. 1990. New light on Myc and Myb. Part I. Myc. Genes \& Dev. 4: 2025-2035.

Lüscher, B., E.A. Keunzel, E.G. Krebs, and R.N. Eisenman. 1989. Myc oncoproteins are phosphorylated by casein kinase II. $E M B O$ J. 8: 1111-1119.

Murre, C., P. Schonleber-McCaw, and D. Baltimore. 1989. A new DNA binding and dimerization motif in immunoglobulin enhancer binding, daughterless, MyoD, and myc proteins. Cell 56: 777-783.

Prendergast, G.C. and E.B. Ziff. 1991. Methylation-sensitive sequence-specific DNA binding by the c-Myc basic region. Science 251: 186-189.

Prendergast, G.C., D. Lawe, and E.B. Ziff. 1991. Association of Myn, the murine homolog of Max, with c-Myc stimulates methylation-sensitive DNA binding and Ras cotransformation. Cell 65: 395-407.

Sadowski, I., I. Ma, S. Triezenberg, and M. Ptashne. 1988. GAL4VP16 is an unusually potent transcriptional activator. $\mathrm{Na}$ ture 335: 559-560.

Sambrook, J., E. Fritsch, and T. Maniatis. 1989. Molecular cloning: A laboratory manual. Cold Spring Harbor Laboratory Press, Cold Spring Harbor, New York.

Sawadogo, M. 1988. Multiple forms of the human genes-specific transcription factor USF. J. Biol. Chem. 263: 11994-12001.

Sarid, J., T.D. Halazonetis, W. Murphy, and P. Leder. 1987. Evolutionarily conserved regions of the human c-Myc protein can be uncoupled from transforming activity. Proc. Natl. Acad. Sci. 84: 170-173.

Seed, B. and J.Y. Sheen. 1988. A simple phase-extraction assay for chloramphenicol acyltransferase activity. Gene 67: 271277.

Stone, J., T. deLange, G. Ramsay, E. Jakobovits, J.M. Bishop, H.E. Varmus, and W.M.F. Lee. 1987. Definition of regions in human c-myc that are involved in transformation and nuclear localization. Mol. Cell. Biol. 7: 1697-1709.

Sun, X.H. and D. Baltimore. 1991. An inhibitory domain of E12 transcription factor prevents DNA binding in E12 homodimers but not in E12 heterodimers. Cell 64: 459-470.

Voronova, A. and D. Baltimore. 1990. Mutations that disrupt DNA binding and dimer formation in the E47 helix-loophelix protein map to distinct domains. Proc. Natl. Acad. Sci. 87: 4722-4726.

Watt, R.A., A.R. Shatzman, and M. Rosenberg. 1985. Expression and characterization of the human c-myc DNA-binding protein. Mol. Cell. Biol. 5: 448-456. 


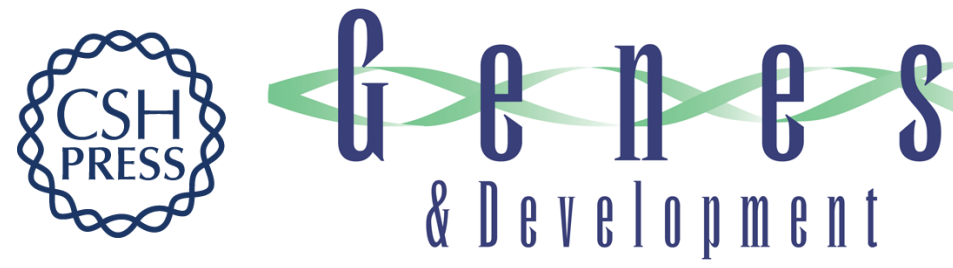

\section{Max: functional domains and interaction with c-Myc.}

G J Kato, W M Lee, L L Chen, et al.

Genes Dev. 1992, 6:

Access the most recent version at doi:10.1101/gad.6.1.81

References This article cites 35 articles, 21 of which can be accessed free at: http://genesdev.cshlp.org/content/6/1/81.full.html\#ref-list-1

License

Email Alerting Service

Receive free email alerts when new articles cite this article - sign up in the box at the top right corner of the article or click here.

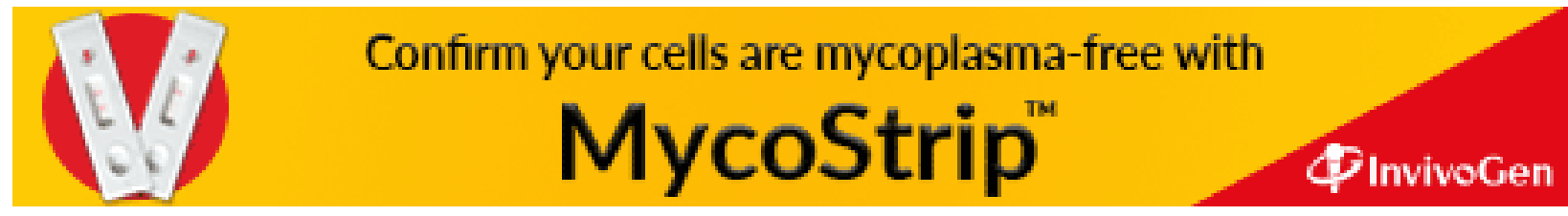

